Article

\title{
Efficacy of Virtual Reality in Painting Art Exhibitions Appreciation
}

\author{
Chih-Long Lin ${ }^{1} * \mathbb{C}$, Si-Jing Chen ${ }^{2}$ and Rungtai Lin ${ }^{2}$ \\ 1 Department of Crafts and Design, National Taiwan University of Arts, New Taipei City 22058, Taiwan \\ 2 Graduate School of Creative Industry Design, National Taiwan University of Arts, New Taipei City 22058, \\ Taiwan; Jing0503@gmail.com (S.-J.C.); rtlin@ntua.edu.tw (R.L.) \\ * Correspondence: CL.Lin@ntua.edu.tw; Tel.: +886-2-22722181-2128
}

Received: 5 March 2020; Accepted: 22 April 2020; Published: 26 April 2020

\begin{abstract}
Virtual reality (VR) technology has been employed in a wide range of fields, from entertainment to medicine and engineering. Advances in VR also provide new opportunities in art exhibitions. This study discusses the experience of art appreciation through desktop virtual reality (Desktop VR) or head-mounted display virtual reality (HMD VR) and compares it with appreciating a physical painting. Seventy-eight university students participated in the study. According to the findings of this study, painting evaluation and the emotions expressed during the appreciation show no significant difference under these three conditions, indicating that the participants believe that paintings, regardless of whether they are viewed through VR, are similar. Owing to the limitation of the operation, the participants considered HMD VR to be a tool that hinders free appreciation of paintings. In addition, attention should be paid to the proper projected size of words and paintings for better reading and viewing. The above indicates that through digital technology, we can shorten the gap between a virtual painting and a physical one; however, we must still improve the design of object size and the interaction in the VR context so that a virtual exhibition can be as impressive as a physical one.
\end{abstract}

Keywords: virtual reality; painting appreciation; virtual exhibition; exhibition experience

\section{Introduction}

Exhibitions are the most common approach for enterprises to promote products, museums to promote their collections, or artists to promote their work. Increasing demand for exhibitions has also caused some problems. First, visitors can only appreciate the collection when they go to a certain place at a certain time. Hence, people affected by problems with transportation or personal scheduling are less interested in attending exhibitions and thus, they are not able to experience such exhibitions. The second aspect is the removal of a collection after the end of an exhibition, which makes it difficult to maintain the special art atmosphere [1]. Therefore, effort should be devoted to overcoming the spatial-temporal limitation so that more people have access to exhibitions. Owing to technological advancements in recent years, physical exhibitions have been virtualized and are no longer confined to a physical building, thus overcoming the spatial-temporal limitation. Such virtualization encompasses web pages and virtual reality (VR), the effects of which prompt further evaluation of exhibitions.

\subsection{Application of $V R$}

Virtual reality (VR) creates a three-dimensional virtual world using computer simulation to simulate visual, aural, and tactile senses such that the users feel as if they are in the real world. VR has revolutionized users' operation by freeing them from instructions and programmed-order models and enabling them to communicate with the system more directly. VR is immersive, interactive, 
and imaginative. The "immersive" feature allows users to integrate themselves into the virtual context and feel as if they are in another world by escaping temporarily from the real world, the "interactive" feature enables users to react even when they touch things in the virtual world; the "imaginative" feature is one by which an imaginary world simulates the real one, with great room for imagination [2].

Many scholars believe that VR has significant potential to improve people's ability to study [3-7]. Apart from education, VR has been applied to many other fields such as psychological research [8], rehabilitation [9], marketing [10], nursing [11], and cultural heritage [12-14]. VR is frequently used in work environment simulation for skill training or for the evaluation of psychological and physiological responses of users. Truschzinski et al. [15] used a VR system to evaluate the emotional states, cognitive workload, and task performance of subjects while performing air traffic control tasks of various difficulties. Alshaer et al. [16] developed a VR powered wheelchair simulator to train and assess the abilities of users to operate vehicles in a controlled and safe manner. Deb et al. [17] created a new pedestrian simulator using VR and confirmed that the simulator is a valid method for capturing pedestrian behavior in a crosswalk scenario. A VR surgery simulation system can provide surgery training to interns or inexperienced doctors, so that, when operating this system, these doctors can feel as if they are performing a real surgery, which helps reduce the risk of errors in future real surgeries [18]. In the field of cultural heritage, due to the progress of computer technology, it is now possible to use reverse engineering to construct and store cultural relics, buildings, and monuments in 3D data, and then, analyze, investigate, preserve, and restore them aided by computer imaging technology [14,19]. Pietroni et al. [12] used a projector-based display and a Kinect sensor to allow users to interact with virtual scenes through motion-sensing aimed at experiencing a virtual reconstruction of the Etruscan Regolini Galassi tomb. Gonizzi Barsanti et al. [14] used photogrammetry to acquire the 3D data of ancient Egyptian artefacts—a wooden sarcophagus and heart scarab—and modelled them for VR visualization. Moreover, the study combined optical and inertial tracking methods to obtain robust pose tracking performance, which allowed users to interact with the displayed virtual scenes through simple hand movements, such as grabbing. Hernández et al. [20] presented an immersive VR system about Castro culture that allows users to physically walk. The system uses a hybrid interface combining a wireless pointing device and inertial and acoustic tracking sensors to determine the user's pose, and to allow users to interact with the displayed virtual environment by physically walking in the digital space. Hsieh et al. [13] investigated the visitors' visiting experience of the Dunhuang cultural relics VR exhibition, and found that the application of VR to a cultural relics display has strong appeal to younger audiences, creates new experiences for audiences, stimulates their learning interest, satisfies their curiosity, and keeps them engaged during their visit.

\subsection{Locomotion/Interaction in $V R$}

VR systems require harmonious coordination among interaction, locomotion, audio, visual, and task design, in order to provide users with a good immersive experience. The locomotion operation will affect users' comfort, dizziness, and convenience. Teleportation is one of the most common locomotion techniques in VR systems [21]. By teleportation, the user uses a joystick or the center of sight, selects a point in the environment, and then moves to it. The dizziness caused by teleportation is relatively negligible. Buttussi and Chittaro [22] compared the influences of joystick, teleportation, and body leaning on the movement completion time, subjective feelings (headache, nausea, eye soreness, and overall feeling), presence, and usability. The research results show that teleportation has the shortest movement completion time, the lowest nausea, and the highest usability, while body leaning has similar results to the joystick, with the exception of the movement completion time, which is shorter than that of the joystick. However, the authors also pointed out that, as there is clear space or only low obstacles between the movement paths, teleportation is better than the other two methods. Bozgeyikli et al. [23] found that when moving around large obstacles, the joystick has a shorter operation time than teleportation, and pointed out that by using teleportation, users tend to lose their sense of direction when teleporting to a destination. Calandra et al. [24] evaluated the influences 
of arm swinging, KATWalk (an omnidirectional treadmill with a containment ring) and walk-in-place on usability, motion sickness, and task performance, and found that KATWalk has significantly lower usability than the other two methods, while the other results are similar, which shows that, instead of using an external assisting device, it is only necessary to hold the joystick with both hands and swing back and forth or install sensors on the lower limbs and simulate walking movements, in order to achieve the same movement effect in the VR environment. Bozgeyikli et al. [25] evaluated eight VR mobile techniques, including redirected walking, walk-in-place, stepper machine, point and teleport, joystick, trackball, hand flapping, and flying, and the results showed that, compared with other methods, point and teleport, joystick, and redirected walking have higher subjective preferences and lower dizziness, which makes them more suitable for room-scale environments. In addition to the handheld joystick, upper-arm swings, lower-limb swings, or body leaning, movement can also be controlled using the head or eyeballs. Qian and Teather [26] evaluated the differences in operation performance among eye-tracking selection, head-tracking selection, and both eye-tracking and head-tracking selection, and the results showed that both the movement time and error rate of the head-tracking selection are the lowest, while both the movement time and error rate of the eye-tracking selection are the highest, which is probably because the eye-tracking system has low accuracy and stability. In addition, the author recommended that the size of the target should be greater than the viewing angle by 3 to facilitate user alignment. The results of Blattgerste et al. [27] are the opposite. The research data showed that the operation time, error rate, and head movement angle of the eye-tracking selection are all lower than those of the head-tracking selection. The author pointed out that the reason may be that the eye-tracking used by the research has better system performance.

\subsection{Impact of Display Device on the Experience of Appreciation}

Currently, in order to encourage audience participation, digital media have been utilized for display device, such as exhibitions on digital lines or VR exhibitions, through which the audience can appreciate art works. According to a survey by Thomas and Carey [28], more than $65 \%$ of the participants stated that a prior glance at an art work on a website can intensify their desire to appreciate the original work. Technology is an attractive tool, but the methods to use technology to bring the essence of an art work to life and to involve the audience in the art scene remain a debatable issue.

The difference between attending a physical exhibition and viewing pictures of the exhibition area has been discussed in the literature. Chen et al. [29] explored the respective impact of these two methods on the process of attending an exhibition, exhibit evaluation, and the experience of the scene. According to their experiment, the experience of attending the exhibition is significantly influenced by the different ways of viewing art. This survey suggests that physical exhibitions should be equipped with brochures containing close-ups of art works, and the material and style of all the works in an area should reflect the exhibition theme. Consequently, visitors can have a consistently good experience of appreciation of art. For people viewing exhibits through a screen, Horn et al. [30] explored how the display device, namely a physical exhibit and its screen image, influence the interaction with the audience. The results show that both types of display device can help the audience grasp the theme of the exhibits, but most participants believed that physical products are more enchanting, and hence, they were willing to spend more time interacting with them. A digital image can highlight what our naked eyes tend to overlook, modify or add new elements to works, or present the atmosphere of a work or the history or techniques behind a relic. A digital image can also use the images captured by technological equipment to extend the visual experience of our naked eyes and show the content and history of a work via a series of imaging technologies and visual effects [31]. Antonietti and Cantoia [32] compared the subjects' perception and understanding of the paintings under the viewing modes of paper copy painting and Desktop VR, and found that when the subjects watched on Desktop $\mathrm{VR}$, it was easier for them to connect their personal experience with the content of the paintings, and thus, generate more abstract thinking reactions; for example, they could tell what objects were in the painting and ask why or how. Therefore, appreciating paintings with Desktop VR allows subjects 
to have more abstract ideas and imagination. Usui et al. [33] evaluated subjects' feelings under the viewing modes of paper reproduction painting and HMD VR, and pointed out that, as HMD VR can present the true size of the paintings and enable subjects to view from various angles, it can increase the interest and preference of subjects, and they can have better subjective feelings than the paper copy painting. However, it is necessary to pay attention to visual fatigue and slight dizziness.

$\mathrm{Yu}$ and Lin [34] provided questionnaires to query the audience about their satisfaction with the 3D virtual relic exhibition system. The results indicated the audience's satisfaction with this system and their preference for an introduction with videos or models versus that with only words or static images. The audience believed that a more dynamic introduction can help them learn about the exhibits and improve their experience of attending an exhibition. Another investigation group composed of Hsu et al. [35] explored the impact of four types of display equipment (3D imaging on big screen, flat imaging and words, VR, and multimedia audio and video) on the thoroughness of the audience's experience. The results show that the audience's feelings varied when the same content was shown through different devices. The audience preferred the content and design of VR and 3D imaging on a large screen, because they believed that these two tools, compared with static information or flat dynamic audio and video, were more effective as they transmit multi-dimensional and dynamic images that capture the audience's attention and help them absorb the information conveyed to them. Higuera-Trujillo et al. [36] selected an interior shopping environment as a scene and compared the difference of psychological and physiological responses of subjects between physical environments, photographs, 360 degree panoramas, and VR. The results showed that, compared with the photograph medium, both 360 degree panoramas and VR more closely approached the physical environment. Several studies have shown that VR systems contribute to improving the quality of user experience, but there are several weaknesses of VR systems that cannot be ignored; for example, the construction of virtual scenes and objects requires professional skills and knowledge [37]. VR devices are required, and the display effects depend on the device specifications [38]. In addition, the movement and interaction modes in the VR environment affect the usability and comfort [22], which requires special attention.

\subsection{Research Purpose}

In terms of art exhibitions, major museums in the world held over 700 exhibitions in 2018, attracting a total number of nearly 130 million visitors. The Louvre Museum in Paris and the National Museum of China in Beijing were the top two museums regarding the number of exhibition visitors, with an annual figure of over 8 million people [39]. Over a million people appreciate works of art in a traditional manner; nowadays, with the advancement of VR, we have the possibility to look at such works from a different perspective. Despite the different display media, artworks are teeming with profound thoughts and artistic values. Moreover, digital artworks are not the original artworks, but rather are computer digital images obtained from capturing photos of the original works; hence, when they are shown on a screen, the colors, size, and multi-dimensional effects will vary [40]. VR can create an immersive atmosphere, but whether the experience of viewing paintings in a VR environment is similar to that of physical paintings is a question that this study intends to explore. Moreover, this study proposes some suggestions on the design of virtual display devices for the purpose of better virtual exhibition appreciation.

\section{Materials and Methods}

\subsection{Paintings}

This study evaluated paintings by Miss Sandy Lee, an amateur painter who started to learn painting in 2008. She was tutored from 2008 to 2009, and from 2009 to 2012, she joined a painting school to work with other students of art and practice under the guidance of teachers. Most of her paintings painted after 2013 were originals. This study selects 12 paintings as samples, which are illustrated in Figure 1. The size of each painting is $41 \times 31 \mathrm{~cm}$ excluding the frame and $62 \times 52.5 \mathrm{~cm}$ 
including the frame. Among these 12 paintings, A, B, D, E, G, H, and J are landscape paintings and the other five $(\mathrm{C}, \mathrm{F}, \mathrm{I}, \mathrm{K}$, and $\mathrm{L})$ are abstracts.

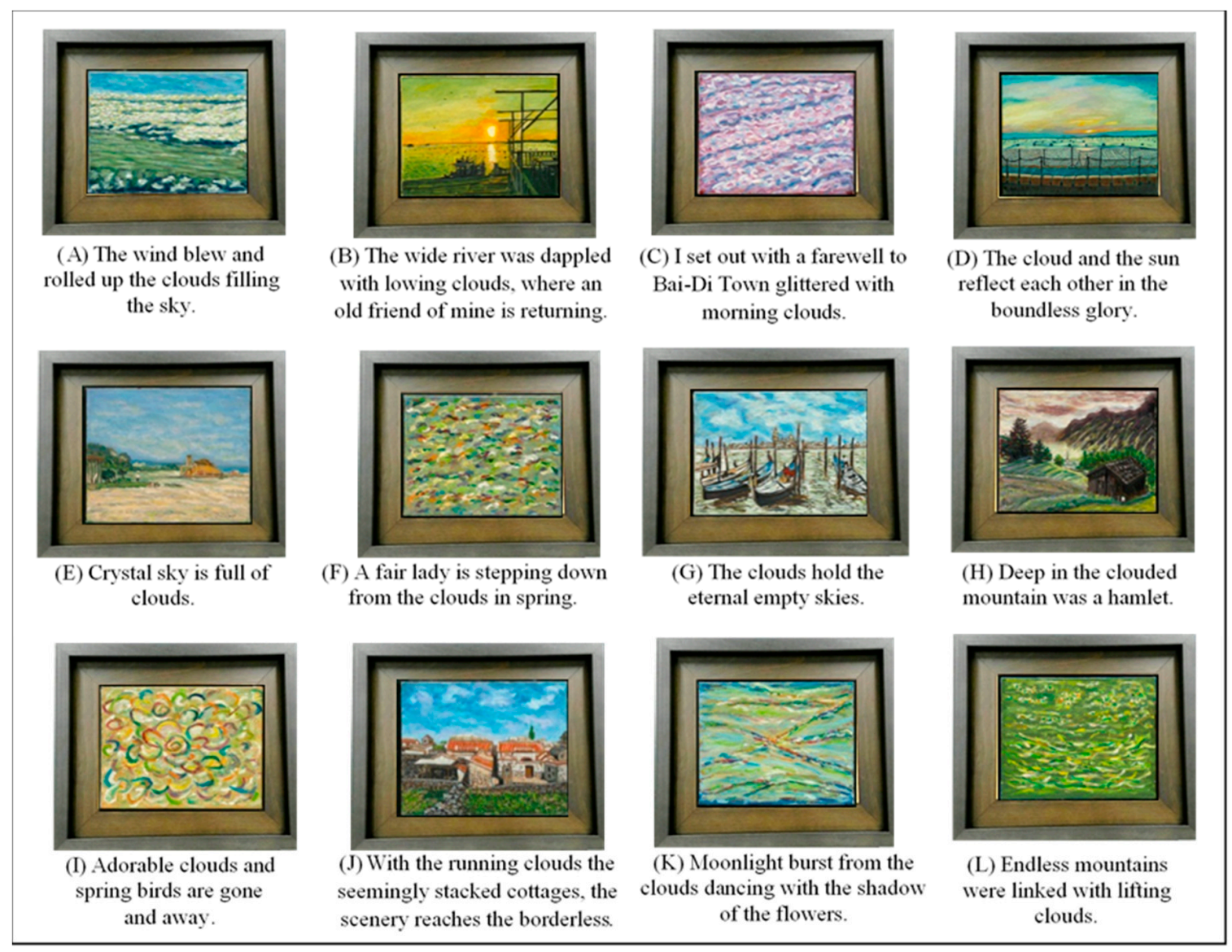

Figure 1. The twelve original paintings of this study.

\subsection{Participants}

Seventy-eight university students ( 19 male and 59 female) participated in the experiment. The mean age of the male participants was $21.17(\mathrm{SD}=6.38$ ) years. The mean age of the female participants was $20.40(\mathrm{SD}=1.59)$ years. The researchers randomly assigned 26 subjects to each experimental condition, meaning the subjects could not choose the experimental conditions. Seven men and 19 women were assigned to the physical entity group, three men and 23 women were assigned to the desktop VR group, and nine men and 17 women were assigned to the head-mounted display (HMD) VR group. There were cases where females were in the majority and the numbers of males were not uniform in each experimental condition due to a large number of young females who volunteered to participate in this study. Under each experimental condition, the researchers randomly assigned the research subjects.

\subsection{Experimental Design}

\subsubsection{Independent Variables}

The independent variables in this experiment were painting display device, including physical paintings, desktop VR, and HMD VR. Further details are as follows. 


\section{Physical Painting Exhibition}

In the study, a classroom of coverage $7 \times 4.8 \mathrm{~m}$ was selected as the exhibition scene. Twelve paintings were hung on the wall according to a certain order. There were two walls in the room accompanied by visual hanging scrolls, and the room after decoration is shown in Figure 2.

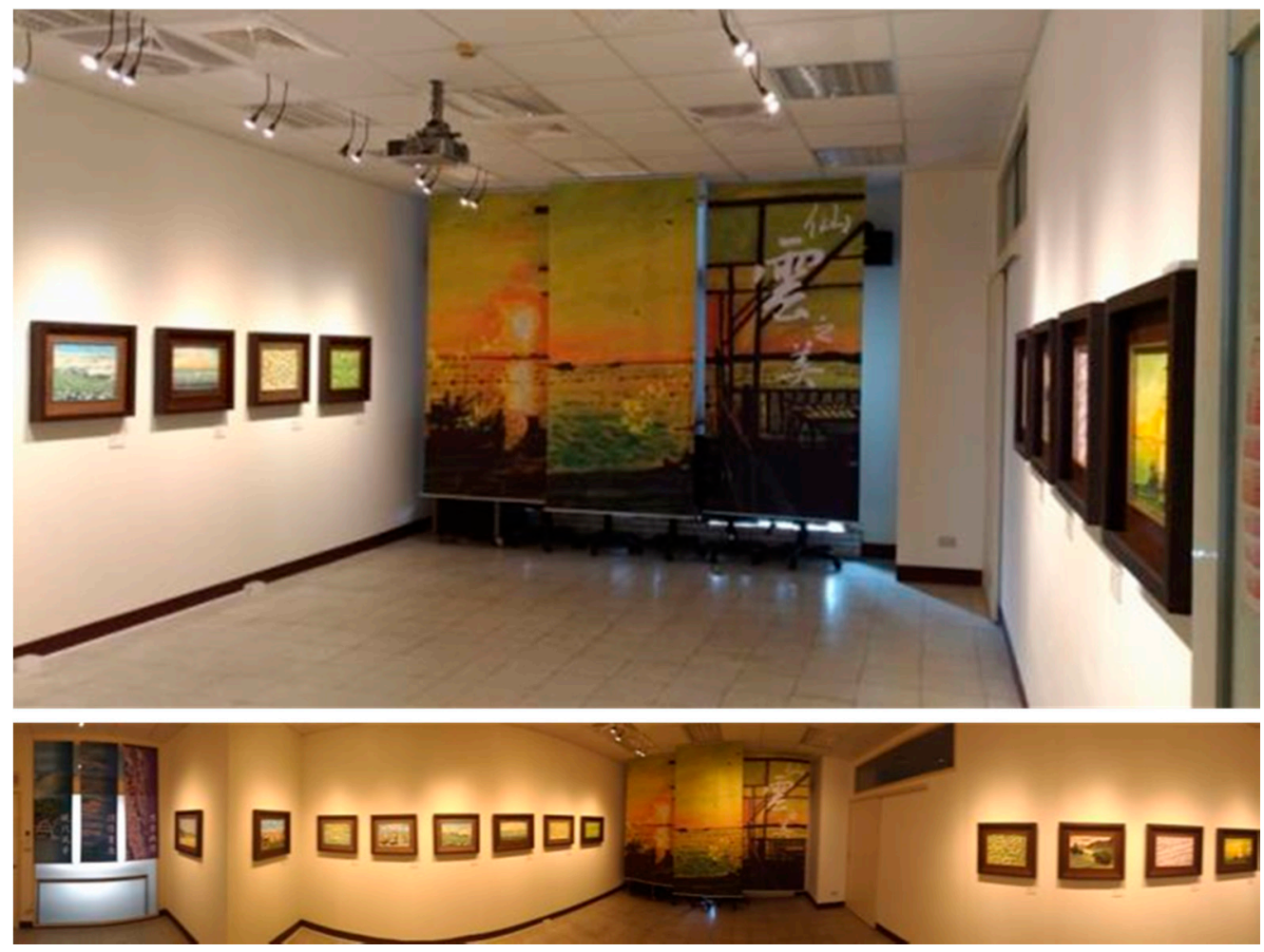

Figure 2. Exhibition of physical original works. The photo on top is the decoration of auxiliary visual hanging scrolls and the photo on bottom is the $360^{\circ}$ panoramic scene.

\section{Desktop Virtual Reality (Desktop VR)}

The exhibition was viewed with desktop VR is shown in Figure 3. In this study, panoramic photos were captured with a digital camera, whose center was the spinning axis so that the camera could capture multiple photos of the surroundings. These photos were thereafter processed, including the correction of slant and bent images and image stitching, and the light variation among the images was adjusted. Subsequently, a cylindrical panorama was constructed from all the images. This study set three observation points in the exhibition and used multimedia web technology to simulate and display the dynamic panoramic images combined with the web page structure. After logging into this web page, visitors could click the sign of the "white arrow" on the floor and move to that place immediately. They could thereafter move the mouse to change the position of viewing. There was a quadrangle pattern under each painting, which could be clicked with the mouse to present the magnified image and the title of the work, as shown in Figure 3. 


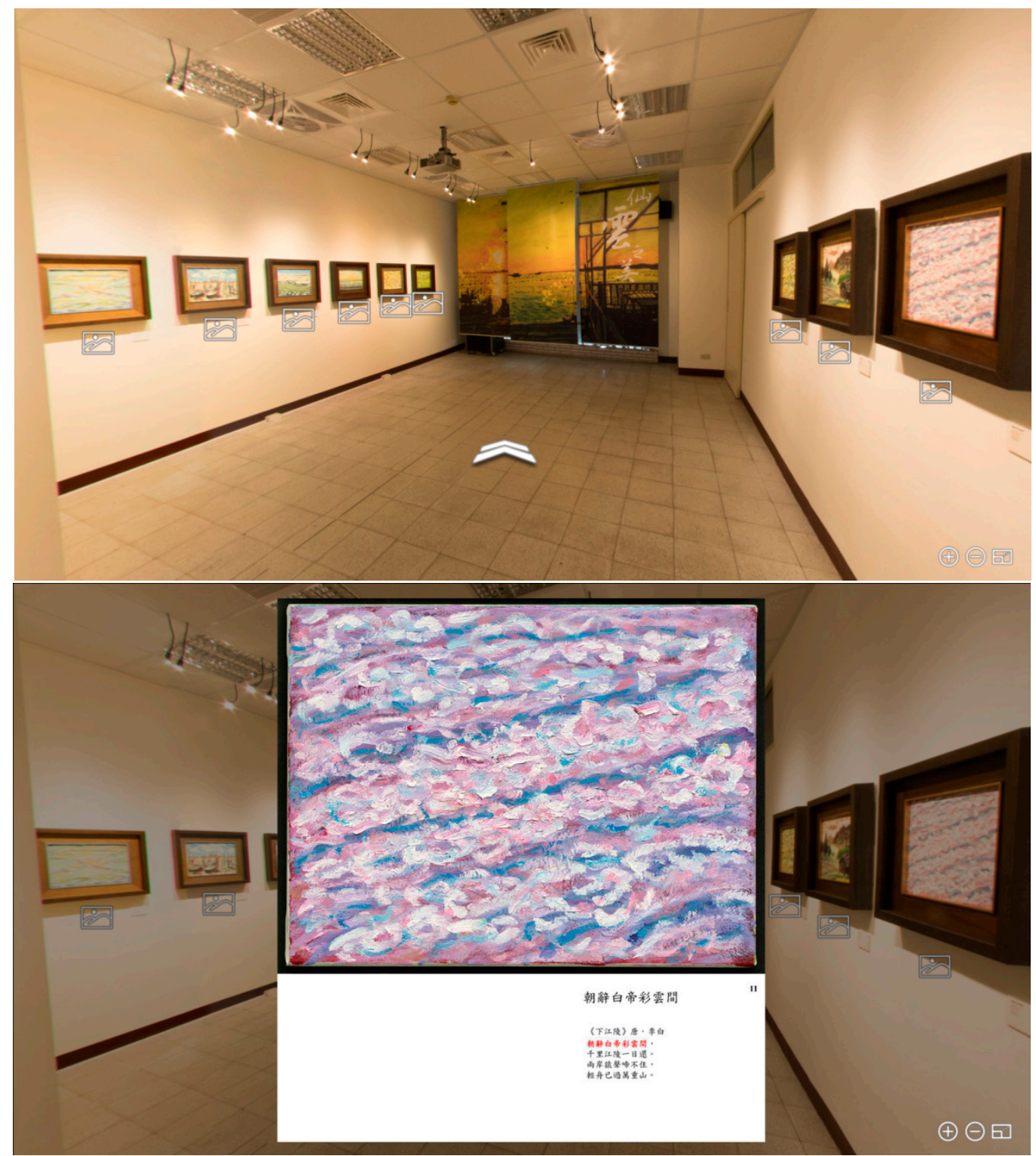

Figure 3. Painting exhibition with Desktop VR. The figure on the top is the whole space seen from the door and the figure on the bottom is the magnified image of one of the paintings.

Head-Mounted Display Virtual Reality (HMD VR)

HMD VR is a virtual exhibition area inspired by the decoration of physical exhibitions and constructed with 3Ds Max. After its completion, the electronic files of 12 paintings were inserted and subsequently, the UNITY software integrated the scene and HMD. This was carried out in the form of a mobile application (App). Viewers could download the App and turn it on, and the exhibition was presented on the mobile phone as shown in Figure 4. The mobile phone was thereafter connected to the VR glasses which were mounted on the head. When viewers turned their heads, the image on the mobile phone would rotate simultaneously. This study intended that the subjects would focus on viewing the paintings; therefore, a movement method similar to the point and teleport in the study of Bozgeyikli et al. [25] was used. When there were no obstacles between the motion paths, this movement method was suitable for the VR environment. In this scene, viewers moved with the gaze-point at the middle of the image. When the gaze-point froze on a painting, the mobile phone could zoom into the painting (lower left of Figure 4). When the gaze-point froze on a painting card, it could be zoomed in 
and presented in the image (lower right of Figure 4). If viewers wanted to close the painting card, they moved the gaze-point to the $\otimes$ sign on the upper right; otherwise, the card remained as it was.
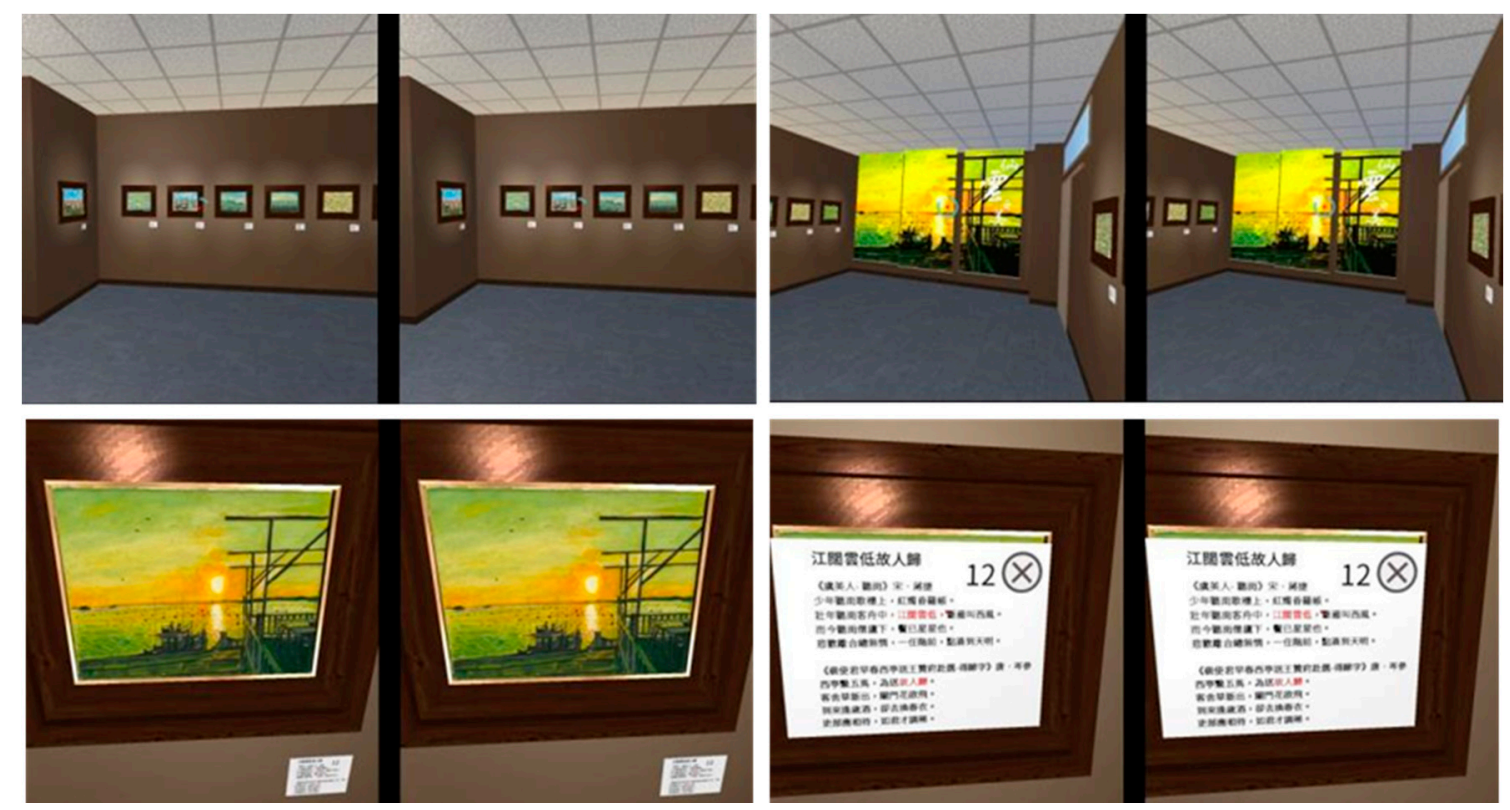

Figure 4. Painting exhibition with HMD VR. The photo on the upper left is the wall in the left of the exhibition area, the photo on the upper right is the auxiliary visual hanging scroll, the photo on the lower left is the magnified image of one of the paintings, and the photo on the lower right is the magnified image of the art work card.

\subsubsection{Dependent Variables}

The dependent variables in this study are presented in the questionnaire on the participants' experience. The first part is the basic information, including gender, age, and latest academic title; the second part is a questionnaire on the exhibition experience, which had been obtained from the research of Hsieh [41]. The options include "pleasure," "relaxed," "calm," "having access to all the works I like," "originality," "attractive," "precious," "the works make me feel the form or meaning of cloud," "the title can intensify my interest in the painting," "I would like to hang this painting in my house," and "preference." Each question was be evaluated with 1 point (strongly disagree), 2 points (disagree), 3 points (fair), 4 points (agree), or 5 points (strongly agree). The third part was to select three favorite paintings from among these twelve and indicate their numbers.

\subsection{Experiment Procedure}

The researchers first explained the experimental purpose and process to the subjects, and then, randomly selected the experimental conditions of the subjects. Each participant only viewed through a single medium to avoid learning effects. Participants either viewed the physical original works in an exhibition room or participated in one of two VR experiments in the office. In the experiment with desktop VR, the participants viewed the works through a 22-inch liquid crystal screen (brand: ASUS; No. VW228) and controlled the direction with a mouse (left of Figure 5). In the experiment with HMD VR, the participants used a mobile phone (brand: ASUS; No. Z017DA) to view the VR content. They wore head-mounted VR glasses (brand: KWorld, No. 3D-VRII) and moved their heads to watch their surroundings (right of Figure 5). This experiment did not set a time limitation for viewing, and hence, the participants could decide how long to spend on appreciating each painting, after which they filled out the questionnaire. 

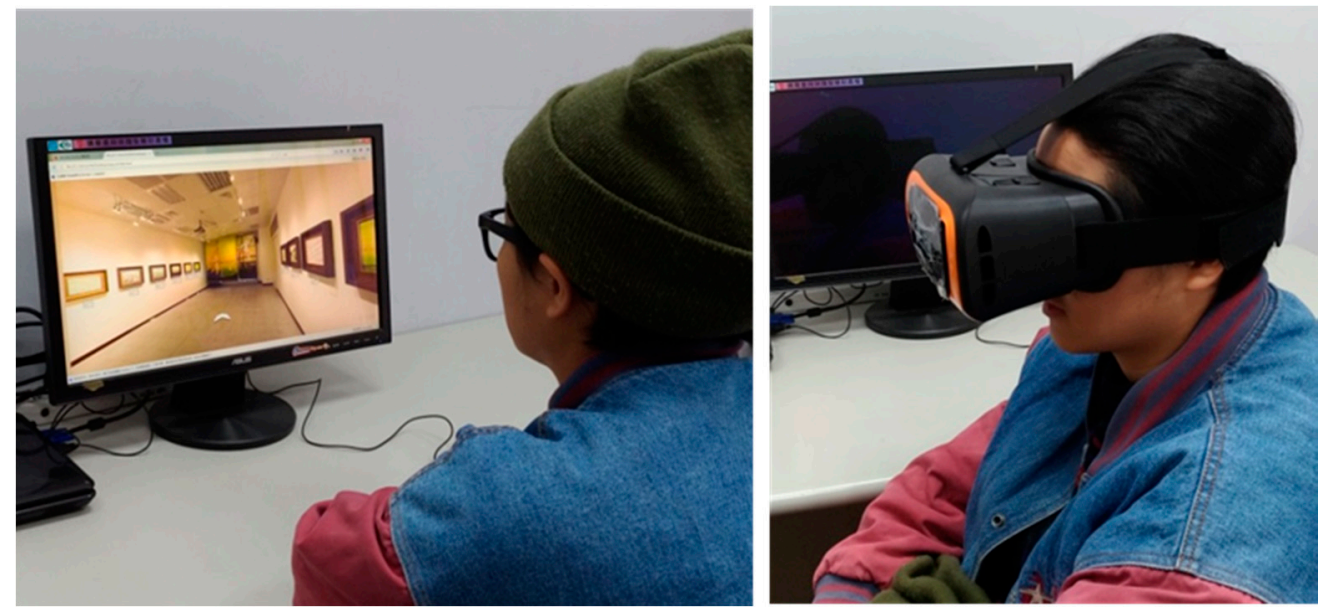

Figure 5. An interviewee is watching with Desktop VR (left) and HMD VR (right).

\subsection{Statistical Analysis}

First, one-way ANOVA was adapted to test whether the impact of the painting exhibition media factor of each question was significant (significance level was set at 0.05). For programs reaching the significance level, we used the Duncan multiple comparative method to test whether there was a significant difference among three averages. In addition, Pearson correlations were performed to determine the inter-variable relationships. (Significance level was set at 0.05).

\section{Results and Discussion}

\subsection{Results of Descriptive Statistics and ANOVA Analysis}

The purpose of this study was to find out whether there are any differences in viewing experience between different display media. According to the results of variation analysis in Table 1, after the three groups of subjects viewed the same painting through one media, they displayed no significant difference in their feelings (i.e., "pleasure", "relaxed", and "calm"), their evaluation of the work (i.e., "originality", "attractive", and "precious"), and their overall preference of the painting (i.e., "preference"). This result indicates that the psychological effect and preference for viewing a painting through Desktop VR or HMD VR are similar to that for viewing the original painting, and that the viewer's evaluation of the painting does not vary greatly depending on the media displayed. The scores of "pleasure" had no significant difference among the three media. Similar results were also found by Higuera-Trujillo et al. [36]. Although the dizziness of the subjects was not investigated in this study, from the results of questions 1 and 2 in the subjective questionnaire, the pleasure and relaxed feelings of subjects in the HMD VR conditions were similar to those in the other two experimental conditions, which shows that dizziness would not have been high; otherwise, the scores of these two feelings would have been low. The movement between paintings was similar to the point and teleport in the study of Bozgeyikli et al. [25] and the teleport method is also considered to be quite suitable for the VR environment because of the low dizziness effect.

It is worth noting that there were significant differences among the three media in the two options of "having access to all works I like" and "the title can intensify my interest in the painting" $(p<0.05$ or more). In terms of the option "having access to all works I like", the scores of Desktop VR (4.1 points) and physical paintings (4.4 points) were significantly higher than that of HMD VR (3.4 points). This result relates to how subjects moved between paintings and how they watched paintings. As mentioned in Section 2.3, Experimental Design, when appreciating physical paintings, viewers had the highest degree of freedom. Viewers could move around the exhibition area to see different paintings and moving forward could help them detect the details, while moving backward the panoramic view of the painting came in sight. With HMD VR, viewers could watch at any direction they wanted, 
but they could not zoom into the image until the gaze-point in the middle of the image targeted a certain painting. The operation of the direction was not intuitive or convenient enough. Even after the introduction card had been read, it remained there until viewers moved their heads to target the gaze-point on the sign of $\mathcal{X}$ on the upper right. Compared with HMD VR, the operation of Desktop VR was more intuitive. After logging in this web page, visitors could click the sign of the "white arrow" on the floor and they could move immediately to that place. They then could move the mouse to change the position of watching. Under each painting there was a quadrangle pattern, which could be clicked with the mouse to present the magnified image and the title of the work. However, with these two types of VR the painting size is fixed without being able to zoom in or out, and so viewers cannot zoom in the paintings at their will to appreciate the details. The above analysis tells us that the operation of the HMD VR in this experiment was imperfect. Apart from being able to watch from all directions, the operation of moving forward and backward should be improved. The more important one is to zoom in and zoom out the paintings. If these three functions and the intuitive interaction can be integrated into a single product, then the experience of watching through VR can be improved.

Table 1. Results of descriptive statistics and ANOVA analysis.

\begin{tabular}{ccccc}
\hline \multirow{2}{*}{$\begin{array}{c}\text { Subjective Questionnaire } \\
\text { ((1-5 points) }\end{array}$} & \multicolumn{4}{c}{ Media for Painting Exhibition } \\
\cline { 2 - 5 } & Physical Paintings & Desktop VR & HMD VR & Significance \\
\hline 1.Pleasure & 3.8 & 3.6 & 3.7 & \\
2.Relaxed & 3.8 & 3.7 & 3.4 & \\
3.Calm & 3.7 & 3.6 & 3.4 & $* 4^{\mathrm{a}}$ \\
4.Having access to all works I like & $4.4^{\mathrm{b}}$ & $4.1^{\mathrm{b}}$ & $3.4^{\mathrm{a}}$ & \\
5.Originality & 3.3 & 3.5 & 3.2 & \\
6.Attractive & 3.1 & 3.3 & 3.1 & $*$ \\
7.Precious & 3.2 & 3.4 & 3.1 & \\
8.Meaning of cloud & 3.5 & 3.4 & 3.1 & \\
9.Title encouragement & $3.6^{\mathrm{a}}$ & $3.6^{\mathrm{b}}$ & $3.1^{\mathrm{a}}$ & \\
10.Hang it in my house & 3.0 & 3.1 & 2.9 & \\
11.Preference & 3.1 & 3.3 & 3.2 & \\
\hline
\end{tabular}

${ }^{*} p<0.05,{ }^{* *} p<0.01,{ }^{* * *} p<0.001 ; \mathrm{a}$ and $\mathrm{b}$ are Duncan ex-post test grouping results. The original description of "meaning of cloud" is "the works make me feel the form or meaning of cloud", the original description of "title encouragement" is "the title can intensify my interest in the painting", and the original description of "hang it in my house" is "I would like to hang this painting in my house".

In terms of the option "the title can intensify my interest in the painting," the scores of desktop VR (3.6 points) and physical paintings (3.6 points) were significantly higher than that of HMD VR (3.1 points). The written introduction card played the same function in these three types of media, but had different influences on the viewers, which may be related to the size of the card. In HMD VR, the size of the introduction card is large, and hence, it almost occupies the entire screen during the presentation (lower right of Figure 4). The visual angle reaches $120^{\circ}$, and hence, reading is difficult in this case and readers are discouraged from reading more; thus, the understanding of the written content is undermined, which adversely influences the experience of viewing paintings. With desktop VR, the size of the words in the introduction card is small (bottom of Figure 3), which is not only aesthetically agreeable, but also reader-friendly. The joint presentation with paintings enables readers to refer to two elements simultaneously. Hence, compared with HMD VR, desktop VR delivers a better effect in terms of word presentation.

\subsection{Correlations Between Measures}

This study used correlation analysis to further understand the relationship between viewing experience, painting evaluation, and overall preference. The correlation analysis is shown in Table 2 . This table only shows the significant relevance between every two variables $(p<0.05)$, and the relevance should be improved for better readability. A significant positive correlation is observed 
among "happy," "relaxed," and "calm," indicating that these three kinds of emotions can affect one another. From the table, we can also observe that a significant positive correlation is observed between "happy" and "relaxed" and among "originality," "attractive," and "precious," indicating that the positive emotion evoked during painting appreciation can help viewers establish positive opinions on paintings, and thus, the painting has great value, and is unique and enchanting to the viewer. Except for the option "happy," all other nine indicators have a significant positive correlation with the favorable feeling toward a painting, among which "the painting makes me see the cloud clearly" and "the title can intensify my interest in the painting" enjoy the highest correlation. This result shows that, apart from the painting itself, the behavioral freedom while watching (how random viewers can behave while watching), the emotion while watching (such as being relaxed and calm), and additional information about the painting (such as the title) can simultaneously affect the viewers' impression of the paintings.

Table 2. Pearson correlation coefficients for the significant measures.

\begin{tabular}{|c|c|c|c|c|c|c|c|c|c|c|c|}
\hline & 1 & 2 & 3 & 4 & 5 & 6 & 7 & 8 & 9 & 10 & 11 \\
\hline 1. Pleasure & 1 & & & & & & & & & & \\
\hline 2. Relaxed & $\begin{array}{l}0.69 \\
* * *\end{array}$ & 1 & & & & & & & & & \\
\hline 3. Calm & $\begin{array}{l}0.51 \\
* * *\end{array}$ & $\underset{* * *}{0.84}$ & 1 & & & & & & & & \\
\hline 4. Having access to all works I like & & $0.37^{* *}$ & $\underset{* * * *}{0.46}$ & 1 & & & & & & & \\
\hline 5. Originality & & $0.23 *$ & $0.29 *$ & & 1 & & & & & & \\
\hline 6. Attractive & 0.24 * & $0.28^{*}$ & $0.30 * *$ & 0.25 * & $\underset{* * *}{0.74}$ & 1 & & & & & \\
\hline 7. Precious & & $0.30^{* *}$ & $0.27^{*}$ & & $\underset{* * *}{0.57}$ & ${ }_{* * * *}^{0.66}$ & 1 & & & & \\
\hline 8. Meaning of cloud & & $0.36^{* *}$ & $0.29^{*}$ & $0.28^{*}$ & $\begin{array}{l}0.45 \\
* * *\end{array}$ & $\underset{* * *}{0.47}$ & $\underbrace{0.54}_{* * *}$ & 1 & & & \\
\hline 9. Title encouragement & & & & & $0.37^{* *}$ & $\underset{* * *}{0.44}$ & $\underset{* * *}{0.52}$ & $\begin{array}{c}0.53 \\
* * *\end{array}$ & 1 & & \\
\hline 10. Hang it in my house & & & & & $0.32 * *$ & $0.38^{* *}$ & $0.37^{* *}$ & $\begin{array}{l}0.55 \\
* * *\end{array}$ & $\underbrace{0.52}_{* * *}$ & 1 & \\
\hline 11. Preference & & $0.25^{*}$ & $0.33^{* *}$ & $0.25^{*}$ & $0.46^{* *}$ & $\underset{* * * *}{0.43}$ & $0.36^{* *}$ & $\underset{* * *}{0.48}$ & $\begin{array}{c}0.52 \\
* * *\end{array}$ & $\underset{* * * *}{0.45}$ & 1 \\
\hline
\end{tabular}

${ }^{*} p<0.05,{ }^{* *} p<0.01,{ }^{* * *} p<0.001$. The original description of "meaning of cloud" is "the painting makes me know the cloud"; the original description of "title encouragement" is "the title can intensify my interest in the painting"; the original description of "hang it in my house" is "I would like to hang this painting in my house".

\subsection{Three Favorite Paintings}

To further determine whether the participants' preference for paintings varied in different types of media, this study invited them to choose their three favorite paintings. Figure 6 shows the proportion of people selecting their favorite paintings among all the participants. In terms of physical paintings, the top three paintings were C (69\%), A (58\%), and B (50\%); in desktop VR, the order was C $(42 \%)$, B (35\%), E (31\%), and G (31\%); in HMD VR, the order was E (42\%), A (38\%), and H (35\%).

With regard to physical paintings, viewers' selected certain paintings a as their favorite, with the average proportion of $\mathrm{A}$ to $\mathrm{D}$ being $52 \%, \mathrm{E}$ to $\mathrm{H}$ being $14 \%$, and I to $\mathrm{L}$ being $9 \%$. With regard to desktop VR, the variation between the most and least popular paintings decreased, with the maximum proportion being $42 \%$, the minimum proportion being $15 \%$, and the average being $25 \%$. Nevertheless, we observe that the average proportion of $\mathrm{A}$ to $\mathrm{D}$ was still $31 \%$, higher than $24 \%$ for $\mathrm{E}$ to $\mathrm{H}$ and $20 \%$ for I to L. This result is similar to the trend for physical paintings. The result indicates that people's preference for a painting viewed through desktop VR remains the same when they view the physical work. 


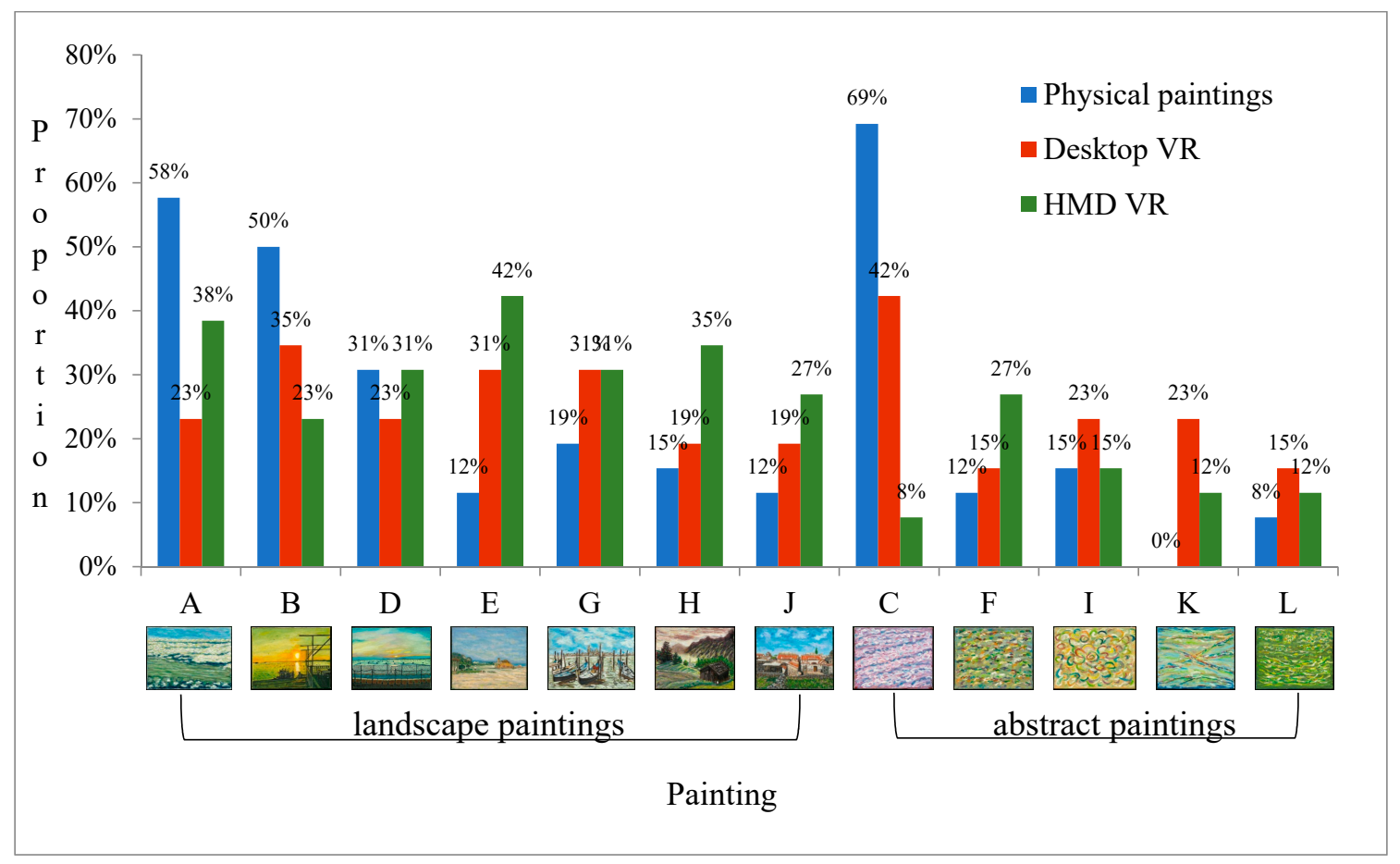

Figure 6. Proportion of each painting being selected as a favorite.

With regard to HMD VR, the popular paintings were different from those under the other two types of experimental conditions-particularly painting $C$, which has been selected by the most participants in the previous two cases but was the least popular in the case of HMD VR. This is attributed to the painting style. Stylistically, these twelve paintings can be divided into landscape paintings (A, B, D, E, G, H, and J) and abstract paintings (C, F, I, K, and L). The average proportion of people selecting landscape paintings as their favorite was 32\% (minimum: $23 \%$, maximum: $42 \%$ ), but the average proportion of people selecting abstract paintings was merely $15 \%$ (minimum: $8 \%$, maximum: $27 \%$ ). The contrast shows that, in the case of HMD VR, abstract paintings are not as popular as landscape ones. The unpopularity of abstract paintings is considered to be related to the size of the image and the viewing quality presented through HMD VR. As an abstract painting is composed of points and lines, there is no specific element intended for cognition and understanding, and hence, only by viewing the whole painting can its essence be sensed. However, with HMD VR, the size of the magnified image of a painting is larger and in this case, the horizontal visual angle reaches $120^{\circ}$. Nevertheless, this angle is difficult for the human eyes to adjust to, because the image presented within $10^{\circ}$ around one's eyes is the clearest one, but the image can be obscured when the angle reaches $30^{\circ}$. Thus, with HMD VR, viewers can only clearly view a part of the painting, but not the whole painting, and hence, the experience of appreciating abstract paintings is poor. By contrast, landscape paintings contain specific elements that enable viewers to organize the whole structure in their minds even if they only view a part of a painting, without affecting the understanding and appreciation of the painting. Compared with HMD VR, in desktop VR, the width of the magnified image of a painting (bottom of Figure 3) presented on a 22-inch screen is $20 \mathrm{~cm}$. Suppose that a viewer is viewing a painting $50 \mathrm{~cm}$ away at a visual angle of approximately $44^{\circ}$, and the viewer can adjust the distance between his or her head and the painting to change the view. Thus, with desktop VR, the whole painting can be viewed clearly, and thus, the experience of appreciating abstract paintings will not be affected significantly.

With respect to the quality of viewing, as HMD VR cannot function without VR glasses, there are convex lens on the left and right lens of the glasses so that viewers can focus the image, the effect of which can influence the quality of viewing. Abstract paintings, owing to their messy structure, require a more accurate image focus; otherwise, viewers will find it cumbersome to obtain a good view of the 
painting. A landscape painting, however, has a certain theme, and hence, the experience of viewing the painting will not be affected even if a part of it is not clearly visible. The VR glasses used in this experiment have no influence on the viewing of landscape paintings, but such an influence remains in the case of abstract paintings. Therefore, the exhibition of abstract paintings requires better focusing for better appreciation.

\section{Conclusions}

This study explored the respective impacts of three types of display media on the participants' experience of viewing and appreciating a painting. According to the experiment results, display media only exert a remarkable impact on two options: "having access to all the works I like" and "the title can intensify my interest in the painting." Owing to the operation and image size differentiation, the scores of these two options were the lowest with HMD VR. In terms of the participants' favorite paintings, the results show that most of the subjects had the same preferences regarding art when viewing as physical paintings and through desktop VR. Moreover, according to the results of correlation analysis, apart from the painting itself (whether it is attractive or not), the behavioral freedom while watching (how random viewers behave while watching), the emotion while watching (such as being relaxed and calm), and additional information about the painting (such as the title and instruction) can simultaneously affect the participants' impression of paintings. The results of this study show that, compared with physical paintings, paintings in VR bring a similar experience to the audience. To develop similar VR exhibitions, this study noted that special attention should be paid to the device specifications and the interaction methods, which do not need to be considered in physical exhibitions, but are key to the users' experiencing depth and satisfaction in VR systems.

This study had several limitations. Firstly, the painting samples in this study were all painted by an amateur artist. If the works of other artists had been included, there could have been differences in image composition, painting skills, and use of color, and the viewing effect may have differed from that in this study in a VR environment. The second limitation was that the age group was narrow, making the results more applicable to 22- to 30-year-old healthy female adults. In the future, the research team will evaluate the experience of males, the elderly, and other ethnic groups in viewing paintings in a VR environment, in order to further understand the differences in the use of VR systems between different subjects. Thirdly, considering that there were only 26 subjects in each experiment in this study, a more general conclusion could be obtained if the number of subjects is increased.

Author Contributions: Conceptualization and methodology, C.-L.L.; investigation, C.-L.L. and S.-J.C.; formal analysis, C.-L.L. and S.-J.C.; writing-original draft preparation, S.-J.C.; writing-review and editing, C.-L.L. and R.L.; visualization, C.-L.L., R.L., and S.-J.C.; All authors have read and agreed to the published version of the manuscript.

Funding: This work was supported by the Ministry of Science and Technology under Grant MOST 106-2628-E-144 -001-MY3.

Acknowledgments: The authors wish to thank Miss Sandy Lee for providing the 12 paintings.

Conflicts of Interest: The authors declare no conflict of interest.

\section{References}

1. Li, J.-C. Exploration of Strategies in Industrial Exhibition: Series Exhibition of Taiwan Telecommunications Industry as a Case Study. Technol. Mus. Rev. 2012, 16, 31-55.

2. Burdea, G.; Coiffet, P. Virtual Reality Technology; Wiley-Interscience: New York, NY, USA, 1994.

3. Chen, Y.-L. The Effects of Virtual Reality Learning Environment on Student Cognitive and Linguistic Development. Asia Pac. Educ. Res. 2016, 25, 637-646. [CrossRef]

4. Yen, Y.-H. Creation and Research on Integrating Virtual Reality and Digital Game-Based Learning to Improve Learning Motivation - A Case Study of Periodic Table; National Taipei University of Technology: Taipei City, Taiwan, 2017. 
5. Ainge, D.J. Upper Primary Students Constructing and Exploring Three Dimensional Shapes: A Comparison of Virtual Reality with Card Nets. J. Educ. Comput. Res. 1996, 14, 345-369. [CrossRef]

6. McLellan, H. Virtual reality and multiple intelligences: Potentials for higher education. J. Comput. High. Educ. 1994, 5, 33-66. [CrossRef]

7. Winn, W.; Bricken, W. Designing virtual worlds for use in mathematics education: The example of experimental algebra. Educ. Technol. 1992, 32, 12-19.

8. Riva, G. Virtual reality: An experiential tool for clinical psychology. Br. J. Guid. Couns. 2009, 37, $337-345$. [CrossRef]

9. Rose, T.; Nam, C.S.; Chen, K.B. Immersion of virtual reality for rehabilitation-Review. Appl. Ergon. 2018, 69, 153-161. [CrossRef]

10. Tsai, T.-Y. A Study of Appling Interactive Virtual Reality to Tourism Experience Marketing; National Taipei University of Technology: Taipei City, Taiwan, 2016.

11. Hsieh, M.-C.; Lin, Y.-H. VR and AR Applications in Medical Practice and Education. J. Nurs. 2017, 64, 12-18.

12. Pietroni, E.; Pagano, A.; Rufa, C. The Etruscanning Project: Gesture-Based Interaction and User Experience in the Virtual Reconstruction of the Regolini-Galassi Tomb. In Proceedings of the 2013 Digital Heritage International Congress (DigitalHeritage), Marseille, France, 28 October-1 November 2013; pp. 653-660.

13. Hsieh, Y.-L.; Chen, C.-H.; Lai, Y.-H. Inspiration and Creativity: Visitor Study of Virtual Reality-Based Museum Exhibition. Museol. Q. 2019, 33, 49-73.

14. Gonizzi Barsanti, S.; Caruso, G.; Micoli, L.L.; Covarrubias Rodriguez, M.; Guidi, G. 3D Visualization of Cultural Heritage Artefacts with Virtual Reality Devices. In 25th International CIPA Symposium; Copernicus Gesellschaft mbH: Göttingen, Germany, 2015.

15. Truschzinski, M.; Betella, A.; Brunnett, G.; Verschure, P.F.M.J. Emotional and cognitive influences in air traffic controller tasks: An investigation using a virtual environment? Appl. Ergon. 2018, 69, 1-9. [CrossRef]

16. Alshaer, A.; Regenbrecht, H.; O'Hare, D. Immersion factors affecting perception and behaviour in a virtual reality power wheelchair simulator. Appl. Ergon. 2017, 58, 1-12. [CrossRef] [PubMed]

17. Deb, S.; Carruth, D.W.; Sween, R.; Strawderman, L.; Garrison, T.M. Efficacy of virtual reality in pedestrian safety research. Appl. Ergon. 2017, 65, 449-460. [CrossRef] [PubMed]

18. Dascal, J.; Reid, M.; IsHak, W.W.; Spiegel, B.; Recacho, J.; Rosen, B.; Danovitch, I. Virtual Reality and Medical Inpatients: A Systematic Review of Randomized, Controlled Trials. Innov. Clin. Neurosci. 2017, 14, $14-21$. [PubMed]

19. Portalés, C.; Lerma, J.L.; Pérez, C. Photogrammetry and augmented reality for cultural heritage applications. Photogram. Rec. 2009, 24, 316-331. [CrossRef]

20. Hernández, L.A.; Taibo, J.; Blanco, D.; Iglesias, J.A.; Seoane, A.; Jaspe, A.; López, R. Physically walking in digital spaces a virtual reality installation for exploration of historical heritage. Int. J. Arch. Comput. 2007, 5, 487-506. [CrossRef]

21. Boletsis, C. The new era of virtual reality locomotion: A systematic literature review of techniques and a proposed typology. Multimodal Technol. Interact. 2017, 1, 24. [CrossRef]

22. Buttussi, F.; Chittaro, L. Locomotion in Place in Virtual Reality: A Comparative Evaluation of Joystick, Teleport, and Leaning. IEEE Trans. Vis. Comput. Graph. 2019. [CrossRef]

23. Bozgeyikli, E.; Raij, A.; Katkoori, S.; Dubey, R. Point \& Teleport Locomotion Technique for Virtual Reality. In Proceedings of the 2016 Annual Symposium on Computer-Human Interaction in Play, Austin, TX, USA, 16 October 2016; pp. 205-216.

24. Calandra, D.; Lamberti, F.; Migliorini, M. On the Usability of Consumer Locomotion Techniques in Serious Games: Comparing Arm Swinging, Treadmills and Walk-in-Place. In Proceedings of the 2019 IEEE 9th International Conference on Consumer Electronics (ICCE-Berlin), Berlin, Germany, 8-11 September 2019; pp. 348-352.

25. Bozgeyikli, E.; Raij, A.; Katkoori, S.; Dubey, R. Locomotion in virtual reality for room scale tracked areas. Int. J. Hum. Comput. Stud. 2019, 122, 38-49. [CrossRef]

26. Qian, Y.Y.; Teather, R.J. The Eyes Don't Have it: An Empirical Comparison of Head-Based and Eye-Based Selection in Virtual Reality. In Proceedings of the 5th Symposium on Spatial User Interaction, Brighton, UK, 16-17 October 2017; pp. 91-98. 
27. Blattgerste, J.; Renner, P.; Pfeiffer, T. Advantages of Eye-Gaze Over Head-Gaze-Based Selection in Virtual and Augmented Reality Under Varying Field of Views. In Proceedings of the Workshop on Communication by Gaze Interaction, Warsaw, Poland, 15 June 2018.

28. Thomas, W.A.; Carey, S. Actual/Virtual Visits: What Are The Links? In Proceedings of the International Conference of Museums and the Web, Vancouver, BC, USA, 18-21 April 2018.

29. Chen, J.-L.; Chen, S.-J.; Lin, C.-L. The Impact of an Actual Visit and Photograph Watching of an Exhibition on Visitor Viewing Experience. In Cross-Cultural Design. Cultural Differences in Everyday Life, Proceedings of the 5th International Conference, CCD 2013, Held as Part of HCI International 2013, Las Vegas, NV, USA, 21-26 July 2013; Rau, P.L.P., Ed.; Springer: Berlin/Heidelberg, Germany, 2013; pp. 269-278.

30. Horn, M.S.; Solovey, E.T.; Crouser, R.J.; Jacob, R.J.K. Comparing the Use of Tangible and Graphical Programming Languages for Informal Science Education. In Proceedings of the SIGCHI Conference on Human Factors in Computing Systems, Boston, MA, USA, 13-17 April 1986; pp. 975-984.

31. Yang, L.-Y. The Influence of Digital Technology on Aesthetic Visual Perception: A Case Study of Digital Images of Art Works in National Palace Museum; Taipei National University of the Arts: Taipei City, Taiwan, 2011.

32. Antonietti, A.; Cantoia, M. To see a painting versus to walk in a painting: An experiment on sense-making through virtual reality. Comput. Educ. 2000, 34, 213-223. [CrossRef]

33. Usui, S.; Sato, K.; Horita, T. Prototyping and Evaluation of Display Media using VR for Art Appreciation Education at School. Int. J. Learn. Technol. Learn. Environ. 2018, 1, 25-40.

34. Yu, H.-K.; Lin, J.Q.-P. Level of Visitor Satisfaction with New Museum Interpretive Media Technology. Museol. Q. 2006, 20, 35-53.

35. Hsu, Y.-H.; Chen, Y.-H.; Huang, Y.-H. An Inquiry on Interpretation Effects via Different Digital Exhibits in National Museum of Marine Biology and Aquarium: A Case of the "Ancient Ocean Gallery". Technol. Mus. Rev. 2014, 18, 5-37.

36. Higuera-Trujillo, J.L.; López-Tarruella Maldonado, J.; Llinares Millán, C. Psychological and physiological human responses to simulated and real environments: A comparison between Photographs, $360^{\circ}$ Panoramas, and Virtual Reality. Appl. Ergon. 2017, 65, 398-409. [CrossRef] [PubMed]

37. Zhang, K.; Suo, J.; Chen, J.; Liu, X.; Gao, L. Design and Implementation of Fire Safety Education System on Campus Based on Virtual Reality Technology. In Proceedings of the 2017 Federated Conference on Computer Science and Information Systems (FedCSIS), Prague, Czech Republic, 3-6 September 2017; pp. 1297-1300.

38. Mittelstaedt, J.; Wacker, J.; Stelling, D. Effects of display type and motion control on cybersickness in a virtual bike simulator. Displays 2018, 51, 43-50. [CrossRef]

39. Sharpe, E.; Silva, J.D. Art's most popular exhibition and museum visitor figures 2018. The Art Newspaper, 27 March 2019.

40. Hazan, S. The Digital Exhibition-Considered in the Long Term. Uncommon Cult. 2015, 6, 12-19.

41. Hsieh, H.Y. Taiwanese Version of the PAD Emotion Scales. In Proceedings of the 2011 Conference of Taiwan Institute of Kansei, Kaohsiung, Taiwan, 2 December 2011.

(C) 2020 by the authors. Licensee MDPI, Basel, Switzerland. This article is an open access article distributed under the terms and conditions of the Creative Commons Attribution (CC BY) license (http://creativecommons.org/licenses/by/4.0/). 